\title{
Effect of Biomass-Burning Emissions on Soil Water Repellency: A Pilot Laboratory Study
}

\author{
Vera Samburova ${ }^{1,2, *}$, Rose M. Shillito ${ }^{3,4}$, Markus Berli ${ }^{3, *}$, Andrey Y. Khlystov ${ }^{1}\left(\mathbb{D}\right.$ and Hans Moosmüller ${ }^{1}(\mathbb{D})$ \\ 1 Division of Atmospheric Sciences, Desert Research Institute, Reno, NV 89512, USA; \\ Andrey.Khlystov@dri.edu (A.Y.K.); Hans.Moosmuller@dri.edu (H.M.) \\ 2 Department of Physics, University of Nevada-Reno, Reno, NV 89557, USA \\ 3 Division of Hydrologic Sciences, Desert Research Institute, Las Vegas, NV 89119, USA; \\ Rose.M.Shillito@erdc.dren.mil \\ 4 Coastal Hydrology Laboratory, US Army Engineer Research and Development Center, \\ Vicksburg, MS 39180, USA \\ * Correspondence: vera.samburova@dri.edu (V.S.); markus.berli@dri.edu (M.B.)
}

Citation: Samburova, V.; Shillito,

R.M.; Berli, M.; Khlystov, A.Y.;

Moosmüller, H. Effect of

Biomass-Burning Emissions on Soil Water Repellency: A Pilot Laboratory Study. Fire 2021, 4, 24. https:// doi.org/10.3390/fire4020024

Academic Editor: Alistair M. S. Smith

Received: 6 March 2021

Accepted: 28 April 2021

Published: 5 May 2021

Publisher's Note: MDPI stays neutral with regard to jurisdictional claims in published maps and institutional affiliations.

Copyright: (c) 2021 by the authors. Licensee MDPI, Basel, Switzerland. This article is an open access article distributed under the terms and conditions of the Creative Commons Attribution (CC BY) license (https:// creativecommons.org/licenses/by/ $4.0 /)$.

\begin{abstract}
While western U.S. wildfires have increased in intensity and scale, their impacts on soil chemical composition and hydraulic processes have received little attention, despite increasing erosion, surface runoff and flooding. The relationships between biomass-burning emissions, composition of the soil, fire heat, and soil water repellency are fragmental and sometimes contradictory. Here, we characterized the water repellency of sand (soil surrogate) exposed to Jeffrey pine duff smoke under controlled laboratory conditions. Water drop penetration time (WDPT), effective contact angle, and relative sorptivity of exposed silica sand (soil surrogate) were determined. Sand samples treated with smoke and heat or with cold smoke showed severe-to-extreme water repellency (WDPT > $1020 \mathrm{~s}$ ). Sand samples exposed to fulvic acid (surrogate for soil organic matter) showed strong water repellency $(\mathrm{WDPT}=81 \mathrm{~s})$ that increased to become severe $(\mathrm{WDPT}=2305 \mathrm{~s})$ after subsequent heating to $200{ }^{\circ} \mathrm{C}$ for two hours. All sand samples exposed to either fire emissions or fulvic acid showed WDPTs $>81 \mathrm{~s}$, effective contact angles between $78^{\circ}$ and $87^{\circ}$, and relative sorptivities between 0.31 and 0.49 compared with the untreated sand samples, with a WDPT $<0.5 \mathrm{~s}$, effective contact angle of $48^{\circ}$, and relative sorptivity of 1 . This indicates that the sorptivity-controlled water infiltration into treated sand is less than half of that into untreated sand.
\end{abstract}

Keywords: soil; fire-induced soil water repellency (FISWR); silica sand; combustion chamber; biomass-burning emissions; Jeffrey pine duff; soil organic matter (SOM); water drop penetration time (WDPT); contact angle; sorptivity

\section{Introduction}

In the last two decades, the frequency, size, and severity of fires in the western U.S. have increased [1-4], with dry conifer forests being greatly affected by these fires [5-8]. In 2020, the western U.S. experienced a series of mega-sized wildfires [9] across California, Oregon, Nevada, and Washington. A hot and dry climate [10-12] fueled these recordbreaking fires that burned over $32,000 \mathrm{~km}^{2}$, according to a National Interagency Fire Center report [13]. Wildfires not only have major impacts on air quality, human health, vegetation, animals, and the climate [14-17], but they also can greatly affect soil's hydraulic properties $[18,19]$. The increase of fires in recent years poses an important question: what are the short- and long-term effects of fires on soil's hydrologic responses, including water repellency or hydrophobicity [20-22]? Fire-induced soil water repellency (FISWR) can result in the reduction of soil infiltration, which can lead to an increase in surface runoff, erosion, and the potential for flooding [23-25].

The effects of fire on soil water repellency (SWR) have been recognized and studied since the 1960s [22,26-30]. Krammes and DeBano [31] carried out field and laboratory 
studies on SWR and pointed out the importance of SWR for post-fire hydrology. In 1966, DeBano and Krammes [22] hypothesized that FISWR was due to the high temperature (up to $\sim 1100{ }^{\circ} \mathrm{C}$ ) volatilization of litter and surface soil "substances", which permeate and then condense within the soil. DeBano and Krammes [22] and DeBano et al. [30] studied how the soil temperature affects soil water repellency. They found that the most intense water repellency in a soil containing soil organic matter (SOM) was induced by temperatures in the $175-200{ }^{\circ} \mathrm{C}$ range and mainly under dry soil conditions. Little soil water repellency was found for soils heated up to temperatures less than $175^{\circ} \mathrm{C}$. DeBano et al. [27] also reported an increase in the contact angle (i.e., the angle a sessile drop of water forms in contact with the soil at the water-air-soil interface) from $63^{\circ}$ to $90^{\circ}$ for pure quartz sand (0.25-0.5 mm mesh size), $65^{\circ}$ to $85^{\circ}$ for San Dimas lysimeter soil, $61^{\circ}$ to $84^{\circ}$ for Pachappa soil, and $40^{\circ}$ to $90^{\circ}$ for the Morris soil samples after the soil was exposed to heat $\left(760^{\circ} \mathrm{C}\right.$ at the soil surface) and burning emissions from sugarbush (Rhus ovata L.) litter combustion. Scholl [32] studied soil wettability and fire in the Arizona chaparral shrubland and reported that water repellency in the soil surface layer was almost nonexistent after exposure to soil temperatures above $270^{\circ} \mathrm{C}$ but existed within the soil after exposure to temperatures below $270{ }^{\circ} \mathrm{C}$ (contact angle of $81.7^{\circ}$ for $270{ }^{\circ} \mathrm{C}$, compared with a contact angle of $48.2^{\circ}$ for $350^{\circ} \mathrm{C}$ ). The author hypothesized that SWR was probably caused by the presence of organic material condensed in the soil layer, as proposed earlier by Krammes and DeBano [31] and DeBano [33]. In a review on the causes and consequences of FISWR, Letey [23] summarized that temperatures greater than $300{ }^{\circ} \mathrm{C}$ could destroy SWR; however, condensed organic compounds that vaporized during the fire could create very strong water repellency in the lower soil layers.

Several authors showed that water repellency largely depends on the presence of different organic compounds and heating of the soil $[28,29,34-36]$. Heat-induced changes in the chemical composition of the organic compounds could also potentially cause SWR [37,38]. For example, Savage et al. [28] heated samples of naturally water repellent soil, captured the vaporized compounds, and analyzed their water repellent properties. The captured compounds were fractionated, and three components, basically aliphatic hydrocarbons, were identified as water repellent. It is interesting to note that the soil used by Savage et al. [28] was only slightly water repellent in its natural state but became extremely water repellent upon heating. Savage et al. [28] also were among the first to use the water drop penetration time (WDPT) test to measure the degree of SWR. Savage [29] further explored the mechanism of FISWR by burning organic litter of Manzanita (Arctostaphylos sp.) vegetation on the surface of columns of freshly ground, air-dried 30-mesh quartz sand to recreate FISWR under controlled conditions without SOM being present before the burn. The results showed that FISWR was caused by the movement of volatile organic compounds (VOCs) from the burning fuel into the soil during the burn. Similar to Savage et al. [28], three fractions of water repellent compounds were identified as inducing FISWR. After the burn, heat continued moving downward into the soil, and some hydrophobic compounds stayed in the soil while more volatile compounds were removed; thus, the post-burn heating process made the soil more water repellent. Although Savage et al. [28] and Savage [29] were able to extract three distinct fractions of water repellent substances from the soil, they did not further analyze them to yield detailed chemical speciation. They did notice, however, that heating these three fractions increased the oxygen content of each fraction and, therefore, their polarity. Based on Savage et al. [28] and Savage [29], it is safe to conclude that organic compounds, such as SOM or burn-induced VOCs, as well as heat are needed to induce a high degree of FISWR. Atanassova and Doerr [39] showed that laboratory heating of soil to $300{ }^{\circ} \mathrm{C}$ when strong water repellency was observed can result in the formation of aromatic compounds and low molecular weight organic acids ( $<12$ carbon atoms in the structure) that could be linked to SWR properties after heating. More recently, Uddin et al. [40,41] studied a range of biogenic volatile organic compounds (BVOCs) typically found in smoke from the combustion of vegetation. They applied BVOCs to acid-washed quartz sand and measured the level of water repellency of the treated sand by means of molarity of ethanol 
(or MED) drop tests. They also carried out molecular dynamics simulations to explore how the various BVOCs may adsorb onto a quartz surface. Uddin et al. [40] found that none of the BVOC-treated sand became hydrophobic, even at high BVOC concentrations or when heated up to $105^{\circ} \mathrm{C}$. Palmitic acid was the only substance tested that induced water repellency. They concluded that the fire-induced increases in SWR were mainly due to the reorganization of the long-chain aliphatic molecules probably already present in the soil, rather than the addition of fire-induced BVOCs. However, in this study, mainly low molecular weight volatile BVOCs were tested, which likely evaporated during the sample preparation procedure (rotatory evaporation and oven drying), thus resulting in insignificant changes in SWR. It should be noted that the compounds tested by Uddin et al. [40] represented only a small fraction of the compounds in forest fire smoke, which is known to contain significant quantities of less volatile hydrophobic compounds [42-45]. Additionally, Uddin et al. [40,41] did not explore the effects of temperatures higher than $105^{\circ} \mathrm{C}$ on SWR. A recent study by Wu et al. [46] highlighted that peat soils were becoming more water repellent due to the heat-induced thermal decomposition of organic species like fatty acids, polycyclic aromatic hydrocarbons, and different carbohydrates. However, due to the extreme complexity of soil's chemical composition and the large variety of soil types, it is a challenging task to specify what organic substances are responsible for FISWR. Moreover, FISWR also depends on other factors, such as the soil moisture, type of vegetation, depth of affected soil, temperature of the fire, and length of the post-fire time period [47-51].

Even though a number of studies showed correlations between fire, physiochemical soil properties, and SWR, the fundamental relationships between the three are still poorly understood. For example, to our knowledge, there are very few studies on biomass-burning emissions (e.g., from wildfires) and their effects on SWR without the soil being exposed to heat from the fire. In addition, little is known about biomass-burning emissions and soil surface chemistry, which controls soil wettability (parametrized, for example, by the contact angle between the water and soil) and sorptivity, two key soil properties governing the impact of fire on hydrology [52]. In this paper, we tested how fire emissions generated from the burning of Jeffrey pine (Pinus jeffreyi) duff, a fuel representative of commonly burnt wildland fire fuels in the western U.S. [53-55], affect the SWR of pure, air-dried silica sand as a function of the temperature of and proximity to the fire under controlled laboratory conditions. SWR was measured in terms of WDPT, further yielding the effective contact angle and sorptivity.

\section{Materials and Methods}

\subsection{Materials and Methods}

A medium-fine silica sand (0.595-0.125 mm diameter, AGSCO Corporation; Wheeling, IL, USA) was selected as a soil surrogate for all experiments in this study. Shillito et al. [47] used the same type of sand for their experiments on -SWR and soil hydraulics properties. In preparation for the experiments, the sand was cleaned using $0.003 \mathrm{M}$ hydrochloric acid (Fisher Scientific, Fair Lawn, NJ, USA) followed by an extensive rinse with ultra-high purity water $\left(18 \mathrm{M} \Omega \mathrm{cm}^{-1}\right.$ ) produced with an ELGA water system (ELGA ${ }^{\circledR}$ LabWater, Woodridge, IL, USA). After acid washing, the sand was placed into a tray covered with aluminum foil and dried in an oven at $105{ }^{\circ} \mathrm{C}$ for $48 \mathrm{~h}$. The acid-washed and oven-dried sand is hereafter referred to as untreated or "blank" sand. As a proxy for SOM, the Suwannee River fulvic acid standard (2S101F) (International Humic Substances Society (IHSS), St. Paul, MN, USA) was added to a subsample of untreated sand (Table 1). The ash was produced during the burning of Jeffrey pine biomass and collected from the surface of the burning platform after the burns were completed (Figure S3; Supplementary Material (SM)). 
Table 1. Tested sand and ash samples and descriptions of the treatments (*ambient relative humidity in the laboratory was $15 \pm 1 \%)$.

\begin{tabular}{cc}
\hline Sample Name & Description \\
\hline Sample I & Blank sand (acid-washed and oven-dried, then exposed to laboratory air* $)$ at room air temperature \\
Sample II & Blank sand + heat $\left(20{ }^{\circ} \mathrm{C}\right.$ for $\left.2 \mathrm{~h}\right)$ \\
Sample III & Ash \\
Sample IV & Sand under mesh $(\sim 5 \mathrm{~cm}$ between the fire and sand sample $)$ placed under a fire pit \\
Sample V & Sand right near the fire \\
Sample VI & Sample V with $5 \mathrm{~mm}$ removed from the top layer $(\sim 5 \mathrm{~mm})$ \\
Sample VII & Sand right under the fire pit using no mesh \\
Sample VIII & Replicate burn 1 as for Sample VII \\
Sample IX & Replicate burn 2 as for Sample VII \\
Sample X & Smoke was collected on a cartridge loaded with blank sand using a chamber sampling line and medium \\
Sample XI & volume sampler (at room temperature $)$ \\
Sample XII & Sample X with a removed top layer $(\sim 5 \mathrm{~mm})$ \\
Sample XIII & Blank sand + fulvic acid (dried at room temperature $\left.\left(20 \pm 2{ }^{\circ} \mathrm{C}\right)\right)$ \\
\hline
\end{tabular}

The WDPT tests were carried out following the procedures described by BadiaVillas et al. [40] and Zavala et al. [41]. Briefly, sand and ash samples were placed in aluminum containers (diameter of $6 \mathrm{~cm}$ ). The sand (mass of $\sim 40 \mathrm{~g}$ ) and ash surfaces were flattened and smoothed as shown in Figure S3 (SM) so that water droplets would not roll off the surface. Water droplets (mass of $25 \pm 4 \mathrm{mg}$ ) were applied to the sample surfaces using a disposable $2 \mathrm{~mL}$ glass pipette (VWR, Radnor, PA, USA) with a latex bulb (Fisher Scientific, Pittsburg, PA, USA). The glass pipette was graduated by weighing the water droplets with an analytical balance (Mettler Toledo LLC, Columbus, OH, USA). Five to six droplets of ultra-high purity water were placed onto the sample surfaces from a height of $\sim 1 \mathrm{~cm}$, and the WDPT was determined as the average time it took for the droplets to be absorbed by the sand or ash samples (Figure S3; SM).

The water repellency of the sand was also determined in terms of the effective contact angle $\alpha$ of the water on the sand surface. A solid surface with $\alpha=0^{\circ}$ is considered perfectly wettable, while increasing effective contact angles $\left(\alpha>0^{\circ}\right)$ indicate increasing levels of water repellency. Shillito et al. [52] developed an empirical relationship between the WDPT and the effective contact angle for this sand. In their experiments, the sand was first acid-washed then oven-dried. One batch of sand remained untreated ("blank sand"), while the second batch of sand was sprayed with Scotchgard ${ }^{\mathrm{TM}}$ to induce water repellency. Known amounts of treated and untreated sand were mixed proportionally by mass; a "20\% treatment" was comprised of $20 \%$ Scotchgard ${ }^{\mathrm{TM}}$-treated sand and $80 \%$ untreated sand. The effective contact angles for various water repellency treatments were determined by wicking experiments $[56,57]$ as well as by direct measurements using an optical tensiometer (Attension Theta, Biolin Scientific, Gothenburg, Sweden). The WDPT of the water repellent sand treatments were measured as described above, and the average drop times were recorded for the treated sand. Based on these WDPT and effective contact angle measurements, the following empirical relationship between the WDPT (in seconds) and the effective contact angle $\alpha$ was developed:

$$
\cos \alpha=-0.046 \ln (W D P T)+0.417
$$

with a coefficient of determination $\left(R^{2}\right)$ of 0.89 . This equation was used to calculate the effective contact angles associated with the WDPTs of the burn experiments, with the results shown in Table 2. 
Table 2. Values of the water drop penetration time, WDPT, effective contact angle $\alpha$, and relative sorptivity $\mathrm{S} / \mathrm{S}_{0}$ for the 13 studied sample treatments.

\begin{tabular}{|c|c|c|c|}
\hline Sample Name & WDPT [s] & $\left.\alpha\left(\mathrm{WDPT}^{1}\right)^{1}\right]$ & $S / S_{0=48^{\circ}}=f(W D P T)^{2}$ \\
\hline Sample I & $<0.5$ & 48 & 1.00 \\
\hline Sample II & $<0.5$ & 48 & 1.00 \\
\hline Sample III & $<0.5$ & - & - \\
\hline Sample IV & $<0.5$ & 48 & 1.00 \\
\hline Sample V & 1027 & 84 & 0.37 \\
\hline Sample VI & 576 & 83 & 0.39 \\
\hline Sample VII & $>3000$ & 87 & 0.31 \\
\hline Sample VIII & 2844 & 87 & 0.31 \\
\hline Sample IX & $>3000$ & 87 & 0.31 \\
\hline Sample X & $>3000$ & 87 & 0.31 \\
\hline Sample XI & 2535 & 87 & 0.32 \\
\hline Sample XII & 81 & 78 & 0.49 \\
\hline Sample XIII & 2305 & 87 & 0.32 \\
\hline
\end{tabular}

${ }^{1}$ Effective contact angle $\alpha$, calculated using Equation (1). ${ }^{2}$ Relative sorptivity $S / S_{0}$, calculated using Equation (2), assuming $\mathrm{S}_{0}$ was at a maximum $\alpha=48^{\circ}$ (Shillito et al. [52]).

Shillito et al. [52] also established a physically-based model that relates SWR with infiltration through the effective contact angle and sorptivity S, a soil hydraulic property that captures water absorption by the soil as a function of capillary and viscous forces. Shillito et al. [52] showed that the sorptivity was highest for low effective contact angles (low water repellency) and low water content and decreased as the contact angle (water repellency) increased. Shillito et al. [52] also proposed the following empirical relationship between the relative sorptivity $S / S_{0}$ and WDPT (in seconds) for the same sand used in this study:

$$
\frac{S}{S_{0}}=-0.051 \ln W D P T+0.719
$$

where $\mathrm{S}$ is the sorptivity of the treated sand $\left(\mathrm{mm} \mathrm{s}^{-1 / 2}\right)$ and $\mathrm{S}_{0}$ is the sorptivity of the air-dried, untreated sand $\left(\mathrm{mm} \mathrm{s}^{-1 / 2}\right)$ with a coefficient of determination $\left(\mathrm{R}^{2}\right)$ of 0.92 . Note that the specific relationship between the WDPT and $S / S_{0}$ given by Equation (2) is mediaspecific (here, for the sand used in these experiments). It does, however, reflect the impact of the WDPT on early-stage infiltration into water repellent soil, which is controlled by the sorptivity. Through the use of Philip's cumulative infiltration equation, Shillito et al. [52] demonstrated the effect of the altered sorptivity on infiltration; as the sorptivity decreased, so did the infiltration. More details on the theory of infiltration are presented in the SM and Shillito et al. [52]. The WDPT, effective contact angle, and relative sorptivity associated with the experimental burn conditions are shown in Table 2.

\subsection{Fuel Selection and Experimental Set-Up}

Dried Jeffrey pine (Pinus jeffreyi) duff containing needles and small branches was used as biomass fuel for our pilot burning experiments (Figure S4a; SM). As discussed in Section 1, Jeffrey pine duff is representative of fuels burnt in many wildland fires in the western U.S. $[10,53,58]$. The intensity and size of these western U.S. wildfires have increased in the last two decades, with Jeffrey and ponderosa pine (Pinus ponderosa) needles and small branches being dominant fuels [59-61]. These fires are having important effects on human and forest health and on the environment [62,63]. Our fuel samples were collected from the forest floor near Truckee, CA, USA and were stored in black plastic bags at room temperature $\left(20 \pm 2{ }^{\circ} \mathrm{C}\right)$ until used for the combustion experiments.

The set-up of the combustion experiment is presented in detail in Figure S2 (SM). Briefly, $1 \mathrm{~kg}$ of fuel was placed onto the burn platform (ceramic disc) inside of the DRI combustion chamber, which was recently described elsewhere $[64,65]$. During the combustion experiment, an additional $2 \mathrm{~kg}$ of fuel was gradually added onto the burn platform via our fuel delivery system (Figure S4; SM). The duration of the combustion experiment 
was $\sim 1 \mathrm{~h}$. Table 1 summarizes all the prepared and analyzed sand and ash samples. To study how organic species in the smoke affected soil water repellency with an absence of combustion heat, we packed a glass cartridge with blank sand and used a medium-volume sampler to collect smoke with a sampling line at a flow rate of $\sim 85 \mathrm{~L} \mathrm{~min}^{-1}$. The sampling was stopped when combustion ended and no more smoke was present in the chamber. To prepare Sample XII (experimental sand with fulvic acid), a solution of Suwannee River fulvic acid $\left(10 \mathrm{mg} \mathrm{mL}^{-1}\right)$ was made in ultra-high purity water and sprayed over the blank sand (Figure S3; SM), which was then dried at room temperature $\left(20 \pm 2{ }^{\circ} \mathrm{C}\right)$ for at least four hours. The samples after the combustion experiment and fulvic acid sample (Sample XIII), heated at $200{ }^{\circ} \mathrm{C}$, were cooled down to room-temperature $\left(20 \pm 2{ }^{\circ} \mathrm{C}\right)$ prior to WDPT measurements.

\section{Results and Discussion}

\subsection{Sand Treatments, Water Droplet Penetration Time (WDPT), and Water Repellency}

The results of the WDPT test for the 13 different samples are presented in Figure 1. The WDPT classification according to Doerr and Shakesby [66] was used to assess the level of SWR in the current discussion. Untreated sand (Sample I) and untreated sand after heating to $200{ }^{\circ} \mathrm{C}$ for two hours (Sample II) were "wettable" with a WDPT $<0.5 \mathrm{~s}$. The ash sample (Sample III), as well as the blank sand placed under the mesh right below the firepit (Sample IV, Figures S2 and S3), remained "wettable" (WDPT < 0.5 s) as well. Even though Sample IV was notably distinct from the blank sand with deposition of fine ash on the surface (Figure S3, SM), it was not more water repellent than the blank sand (WDPT $<0.5 \mathrm{~s}$ ). Sand placed right near the firepit (Sample V, Figures S2 and S3) appeared to have more brownish spots on the sample surface (Figure S3; SM), and strong-to-severe water repellency $[52,66]$ was measured (WDPT $=1027 \pm 708 \mathrm{~s}$ ) for Sample V. The large variation of WDPTs between replicates was most likely the result of the uneven effect of fuel burning (including the temperature and deposition of biomass-burning organics) on the surface. After the top $5 \mathrm{~mm}$ thick layer of Sample V sand was removed, we found that the WDPT for the sand below was $\sim 50 \%$ lower (Sample VI) than for the sand above (Sample V). The sand sample placed under the firepit with no mesh above it (Sample VII, Figures S2 and S3; SM) showed extreme water repellency with a WDPT $>3000 \mathrm{~s}$ (Figure 1). WDPT measurements were concluded at $3000 \mathrm{~s}$, since a noticeable change in water droplet size was observed due to evaporation rather than infiltration of the droplet after that time. Samples VIII and IX (Figure S3; SM) were replicate burns of Sample VII; they showed extreme levels of water repellency, with WDPT $=2844 \pm 215 \mathrm{~s}$ for Sample VIII and WDPT $>3000 \mathrm{~s}$ for Sample IX (Figure 1). For Sample X, the smoke from the combustion chamber was collected in a cartridge packed with blank sand (Figure S2; SM) to check the effect of biomassburning emissions on the SWR without the effect from fire-induced heating of the sand. We found that cold smoke also induced extreme water repellency in the sand in Sample $X$ (WDPT > $3000 \mathrm{~s}$, Figure 1) and, even after removing the top $5 \mathrm{~mm}$ thick layer of sand (Sample XI), the water repellency was still at an extreme level (WDPT $=2535 \pm 895 \mathrm{~s}$ ). It is important to note that for Sample X, the water repellency level (WDPT > $3000 \mathrm{~s}$, Figure 1) was similar to those of the samples placed under the fire pit (Samples VII-IX), and it was almost three times higher than that of the sample placed right near the firepit (Sample V). These results are not in agreement with the study by Uddin et al. [40], where a few selected BVOCs showed insignificant effects on inducing water repellency. This is probably because the majority of the BVOCs tested by Uddin et al. [40] were low molecular weight volatile organic species (and low volatility hydrophobic compounds typically in fire emissions were not tested) that likely evaporated during the four hours of rotary evaporation and $24 \mathrm{~h}$ of oven-drying at $105^{\circ} \mathrm{C}$ used for sample treatment in that study, which explains the lack of a noticeable change in SWR reported by Uddin et al. [40]. 


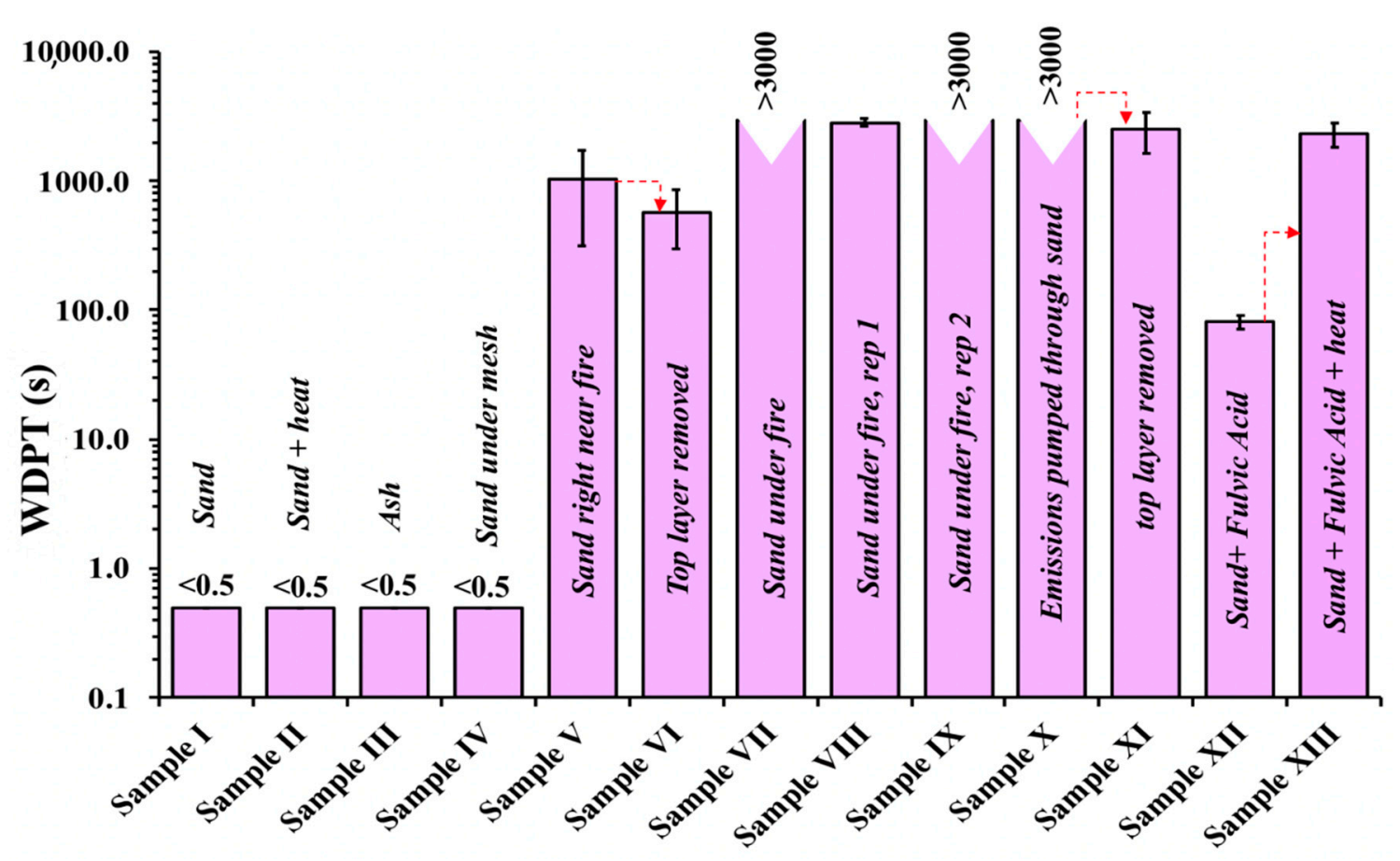

Figure 1. Water droplet penetration time (WDPT) for 13 analyzed samples. Units = seconds (s).

To check how the SOM may affect SWR, we used a fulvic acid mixture as a surrogate for the SOM $[67,68]$. The fulvic acids induced slight water repellency (Sample XII), with WDPT values between 72 and $96 \mathrm{~s}$ (average $=81 \pm 9 \mathrm{~s}$ ). Exposing this sample of fulvic acid-treated sand to a $200{ }^{\circ} \mathrm{C}$ temperature for two hours (Sample XIII) induced an extreme level of water repellency (WDPT $=2304 \pm 479 \mathrm{~s}$ ).

As mentioned above, several studies analyzed the effects of organic compounds and different temperatures on sand wettability, and in the present study, we revisited this question. Within this pilot project, which is the initial step of a large-scale study, we examined the water repellencies of the test sand samples that were placed at different proximities to a pine needle fire (Figure S2; SM). To our knowledge, for the first time, the effect of laboratory-generated cold biomass-burning smoke on the sand wettability properties was investigated, and smoke from a representative western U.S. wildland fuel (Jeffrey pine needles) was used. Moreover, based on our water repellency results, we calculated the relationship between the WDPT and the contact angle for different experimental sand samples (Table 2).

As was expected, the blank sand and ash were wettable (WDPT $<0.5 \mathrm{~s}$ ), which is in good agreement with previous studies [52,69]. For Sample IV, no change in water repellency was observed for the sand that was placed under a mesh right under the firepit. The lack of water repellency in Sample IV's sand was surprising and was most likely due to the absence of organic species on this sand sample, because its position was upstream from the smoke emission. The Sample V sand also had only a small amount of fine ash on its surface (Figure S3; SM), and we concluded that the combination of the temperature and ash did not significantly change the water repellency of Sample IV's sand. Therefore, the sample position relative to the fire and pre-existent organic species in the soil play a key role in forming water repellency during fires, which has been highlighted in several previous studies $[20,30,33]$.

The samples that were placed right near the fire pit (Sample V) or under (no mesh) the firepit (Samples VII-IX) demonstrated extreme water repellency, and this has been observed and discussed in other studies [22,27-30]. This extreme water repellency was likely due to a combination of heat and organic compounds emitted from the combustion, since the blank sand (Sample I) did not contain any organics initially. To check if biomass-burning 
organic species can affect the SWR without the fire's heat, the sand in the glass cartridge was exposed to cold combustion smoke (Sample X) as presented in Figures S2 and S3 (SM). Our results clearly confirm that not only do the organic species, which may already be in the soil, affect water repellency during a fire, but in addition, the organics deposited from the combustion smoke itself can change the water repellency level from almost nonexistent to the extreme. It is known that the chemical properties of SOM and biomass-burning organics are very different [44,70], and further research on the effects of fire smoke on SWR is needed. We also highlight that the amount of biomass-burning organic matter deposited onto the sand samples was not controlled, and thus the water repellency values between Samples VII-IX and Sample X could not be compared.

The fulvic acid-treated sand (Sample XII) was analyzed to check the hypothesis of how SOM may affect water repellency with (Sample XIII) and without (Sample XII) applied heat. This experiment showed that fulvic acids induced only a slight level of SWR (Figure 1), while after the heating of the same sand sample, its repellency increased to an extreme level. This is in line with the findings by Savage et al. [28] about the increase in SWR due to heating. Several authors have attempted to identify the groups of compounds in soils responsible for this repellency change and their chemical transformation during the heating process $[36,39-41,46]$. However, soil organics are highly complex chemical mixtures with different functional groups and molecular weights [71-73], and thus the specific analysis of a single compound of a structure might not be the best strategy for studying soil water repellency. Nevertheless, the changes in water repellency noted for Samples V-XIII were of an order that could significantly decrease infiltration into the soil and subsequently increase runoff production. Therefore, more research is needed on the effects of fires on SOM (e.g., fulvic and humic acids) as well as on organics deposited from combustion smoke to make good predictions of post-fire soil water repellency response.

\subsection{Water Repellency and Hydraulic Properties of Sand and Ash}

Table 2 shows the average water drop penetration time, WDPT, effective contact angle, $\alpha$, and relative sorptivity $S / S_{0}$ for the 13 samples presented in Table 1 . The values for $\alpha$ and $\mathrm{S} / \mathrm{S}_{0}$ were calculated with Equations (1) and (2) based on the average WDPT measurements for the various treatments shown in Figure 1. Samples II and IV showed no apparent change in contact angle or relative sorptivity due to burn treatment compared with the untreated sand of Sample I. This means that infiltration into the sand from Samples II and IV would be no different from the infiltration into the sand from Sample I. The difference between the effective contact angle of $48^{\circ}$ for Sample I, estimated with Equation (1), and the measured effective contact angle of $42^{\circ}$ found by Shillito et al. [52] was likely due to the low accuracy of WDPT recordings $(<0.5 \mathrm{~s})$. The ash of Sample III was not water repellent (WDPT $<0.5 \mathrm{~s}$ ) and, since Equations (1-3) were developed for 40-70 sand and not for ash, they could not be used to estimate the effective contact angle or relative sorptivity calculations.

As shown in Figure 1, the WDPT values indicated severe to extreme levels of water repellency (according to the classification by Doerr and Shakesby [66]) for Samples V-XIII. Table 2 shows the corresponding effective contact angles for Samples V-XIII, ranging from $78^{\circ}$ to $87^{\circ}$, and relative sorptivity, ranging from 0.31 to 0.49 . This means that, in terms of relative sorptivity, infiltration into the sand from Samples V-XIII would be reduced by $51-69 \%$ compared with the infiltration into untreated sand from Sample I. Note that the WDPT tests for Samples VII, IX, and X were ended after 50 min when the first signs of drop evaporation occurred ( $\mathrm{RH}=15 \pm 1 \%$ ), but they were assigned WDPT times of $3000 \mathrm{~s}$ as estimates. Therefore, the WDPTs for Samples VII, IX, and X would likely be higher if the WDPT test were run with evaporation protection (i.e., housed the samples in a closed container during WDPT tests).

The effective contact angles associated with the 13 burn experiments, shown in Table 2 and Figure 2, were within the range of previously published values [31]. Further, Shillito et al. [52] showed that a change in contact angle from $42^{\circ}$ to $88^{\circ}$ corresponded to a decrease in sorptivity that resulted in a significant (34\%) decrease in the 30 min cumulative 
infiltration. Thus, the changes in water repellency due to burning experiments V-XIII would result in measurable differences in pre- and post-burn treatment infiltration.

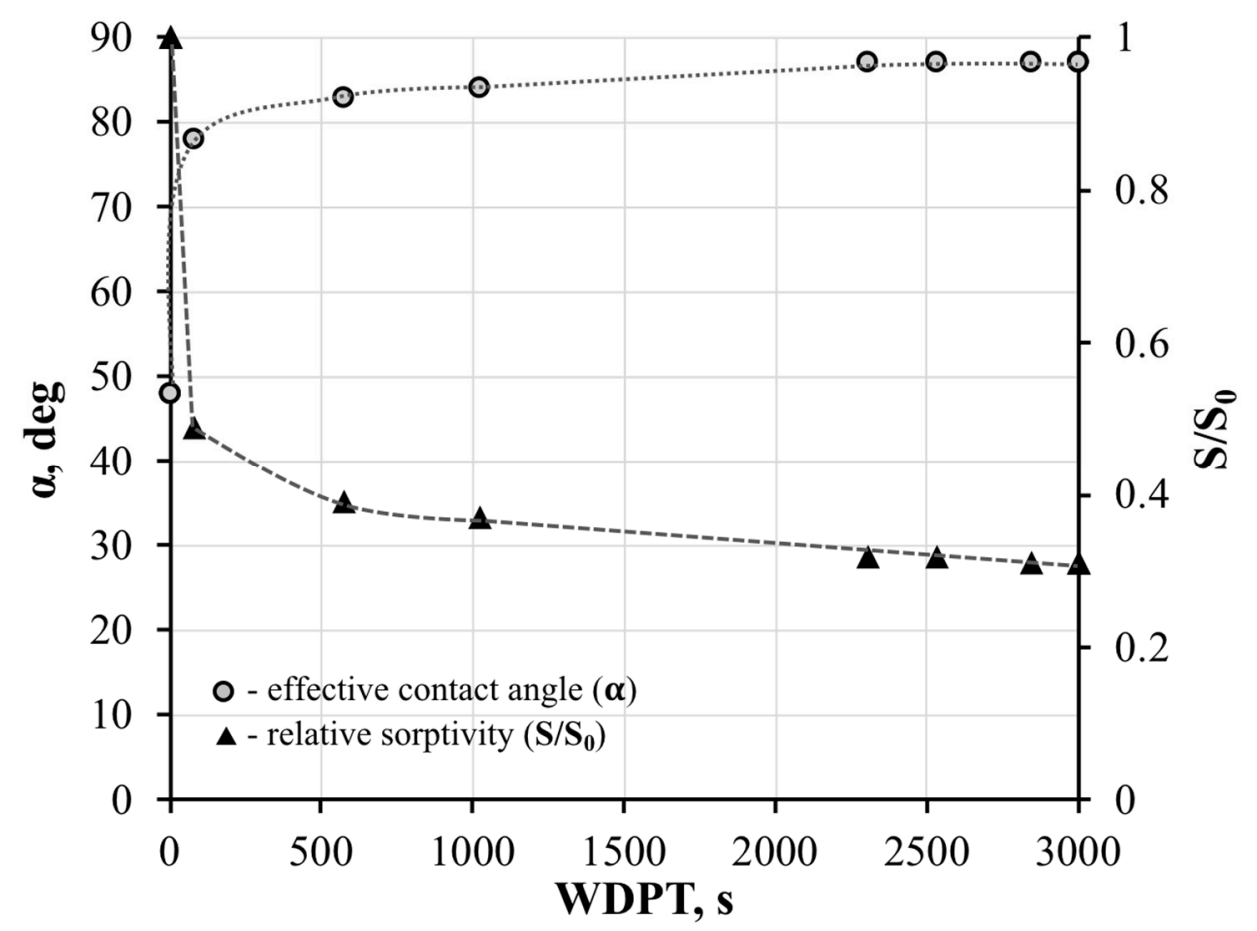

Figure 2. Effective contact angle ( $\alpha$, degrees) and relative sorptivity $\left(\mathrm{S} / \mathrm{S}_{0}\right)$ as functions of water drop penetration time (WDPT, s).

Figure 2 shows the effective contact angle and relative sorptivity values as functions of the WDPT using the data presented in Table 2. The effective contact angles increased and relative sorptivities decreased with the increasing WDPT. Note that most of the contact angle and sorptivity changes occurred at low WDPTs. The effective contact angles, for example, increased from $48^{\circ}$ to $78^{\circ}$ when the WDPT increased from $<0.5 \mathrm{~s}$ to $81 \mathrm{~s}$, but only from $78^{\circ}$ to $87^{\circ}$ when the WDPT increased from $81 \mathrm{~s}$ to more than $3000 \mathrm{~s}$. Similarly, the relative sorptivity decreased from 1 to 0.49 when the WDPT increased from $<0.5 \mathrm{~s}$ to $81 \mathrm{~s}$, but only from 0.49 to 0.31 when the WDPT increased from $81 \mathrm{~s}$ to more than $3000 \mathrm{~s}$. This indicates that lower WDPT values have a comparably larger impact on infiltration, expressed in terms of the relative sorptivitiy, than higher WDPT values. If we assume that early infiltration is dominated by sorptivity (as is typical for rain from short-duration, high-intensity storms infiltrating into initially dry soil), the infiltration capacity would be reduced by $51 \%$ by the WDPT increasing from $<0.5 \mathrm{~s}$ to $81 \mathrm{~s}$, but it would only be reduced by an additional $18 \%$ of the original value by the WDPT increasing from $81 \mathrm{~s}$ to more than $3000 \mathrm{~s}$.

\section{Conclusions}

In this pilot study, we investigated how biomass-burning emissions and the heat of the fire affected SWR. Soil surrogate (i.e., silica sand) samples were exposed to Jeffrey pine duff smoke at different proximities to a pine needle fire under laboratory conditions and to fulvic acid, a surrogate soil organic matter. The WDPT was measured for all samples, and the effective contact angle and sorptivity were calculated. We found that the water repellency of the silica sand samples changed from wettable (WDPT $<0.5 \mathrm{~s}$ ) to severe-to-extreme levels (WDPT > $1000 \mathrm{~s}$ ) after being exposed to smoke and heat or to just cold smoke. These results suggest that the organic compounds from smoke can greatly increase SWR, even in the absence of fire heat. Our experiments with the silica sand samples exposed to fulvic acid confirmed this finding; the SWR of the sand samples 
greatly increased (WDPT = $81 \mathrm{~s}$ ) after being treated with fulvic acid, and the SWR further increased to a severe level (WDPT > 81 s) after subsequent heating at $200^{\circ} \mathrm{C}$. The changes in the calculated contact angles and relative sorptivities showed that sorptivity-controlled water infiltration of the untreated sand can be reduced by more than half after exposure to either fire emissions or fulvic acids with and without the presence of heat. The results of our study highlight the need for future research focused on the fundamental chemistry of SOM during fires and on the effects of combustion smoke organics on SWR with and without the presence of heat.

Supplementary Materials: The following are available online at https: / www.mdpi.com/article/ 10.3390 / fire4020024/s1. Figure S1: DRI combustion chamber with (a) fuel delivery system and (b) burning platform (round ceramic disc on the bottom right); Figure S2: Schema of the combustion experiment; Figure S3: Pictures of the tested samples; Figure S4: (a) Jeffrey pine duff, (b) DRI combustion chamber in use, and (c) combustion in progress (tube on the left is part of the fuel delivery system).

Author Contributions: Conceptualization and methodology, V.S., M.B., R.M.S., A.Y.K., and H.M.; performing the experiments and data collection, V.S.; data processing and analysis, V.S. and R.M.S.; writing-original draft preparation, V.S. and R.M.S.; writing-review and editing, V.S., M.B., R.M.S., A.Y.K., and H.M.; supervision, V.S.; project administration, V.S. and A.Y.K.; funding acquisition, V.S., A.Y.K., and H.M. All authors have read and agreed to the published version of the manuscript.

Funding: This research was supported in part by internal funding from the Division of Atmospheric Sciences, Desert Research Institute and by the National Science Foundation (NSF) under grants AGS-1544425, IIA-1301726 and EAR-1324894.

Institutional Review Board Statement: Not applicable.

Informed Consent Statement: Not applicable.

Data Availability Statement: Data is contained within the article or supplementary material. The data presented in this study are available in the Supplementary Material and/or can be provided via e-mail upon the request (vera.samburova@dri.edu).

Acknowledgments: The authors would like to thank David Campbell for collecting Jeffrey pine duff.

Conflicts of Interest: The authors declare no conflict of interest.

\section{References}

1. Haffey, C.; Sisk, T.D.; Allen, C.D.; Thode, A.E.; Margolis, E.Q. Limits to ponderosa pine regeneration following large high-severity forest fires in the United States Southwest. Fire Ecol. 2018, 14, 143-163. [CrossRef]

2. Westerling, A.L.; Hidalgo, H.G.; Cayan, D.R.; Swetnam, T.W. Warming and earlier spring increase western US forest wildfire activity. Science 2006, 313, 940-943. [CrossRef] [PubMed]

3. Wehner, M.; Arnold, J.; Knutson, T.; Kunkel, K.; LeGrande, A. Droughts, Floods, and Wildfires. Climate Science Special Report; Fourth National Climate Assessment: Washington, DC, USA, 2017.

4. Abatzoglou, J.T.; Williams, A.P. Impact of anthropogenic climate change on wildfire across western US forests. Proc. Natl. Acad. Sci. USA 2016, 113, 11770-11775. [CrossRef] [PubMed]

5. Peterson, D.L. Forest Structure and Fire Hazard in Dry Forests of the Western United States; US Department of Agriculture, Forest Service, Pacific Northwest Research Station: Portland, OR, USA, 2005; Volume 628.

6. Block, W.M.; Finch, D.M. Songbird Ecology in Southwestern Ponderosa Pine Forests: A Literature Review; US Department of Agriculture, Forest Service, Rocky Mountain Forest and Range Experiment Station: Fort Collins, CO, USA, 1997; Volume 292.

7. Cassell, B.A.; Scheller, R.M.; Lucash, M.S.; Hurteau, M.D.; Loudermilk, E.L. Widespread severe wildfires under climate change lead to increased forest homogeneity in dry mixed-conifer forests. Ecosphere 2019, 10, e02934. [CrossRef]

8. Keane, R.E.; Agee, J.K.; Fulé, P.; Keeley, J.E.; Key, C.; Kitchen, S.G.; Miller, R.; Schulte, L.A. Ecological effects of large fires on US landscapes: Benefit or catastrophe? A. Int. J. Wildland Fire 2009, 17, 696-712. [CrossRef]

9. Tedim, F.; Leone, V.; Amraoui, M.; Bouillon, C.; Coughlan, M.R.; Delogu, G.M.; Fernandes, P.M.; Ferreira, C.; McCaffrey, S.; McGee, T.K. Defining extreme wildfire events: Difficulties, challenges, and impacts. Fire 2018, 1, 9. [CrossRef]

10. Gworek, J.R.; Vander Wall, S.B.; Brussard, P.F. Changes in biotic interactions and climate determine recruitment of Jeffrey pine along an elevation gradient. Forest Ecol. Manag. 2007, 239, 57-68. [CrossRef]

11. Crowley, T.J. Causes of climate change over the past 1000 years. Science 2000, 289, 270-277. [CrossRef] [PubMed] 
12. Kusnierczyk, E.; Ettl, G.J. Growth response of ponderosa pine (Pinus ponderosa) to climate in the eastern Cascade Mountains, Washington, USA: Implications for climatic change1. Ecoscience 2002, 9, 544-551. [CrossRef]

13. Report, N.I.F.C. Report: National Large Incident Year-to-Date Report (PDF). Geographic Area Coordination Center, National Interagency Fire Center (Report). 9 October 2020. Available online: https://gacc.nifc.gov/sacc/predictive/intelligence/ NationalLargeIncidentYTDReport.pdf (accessed on 2 March 2021).

14. Burley, J.D.; Bytnerowicz, A.; Buhler, M.; Zielinska, B.; Schweizer, D.; Cisneros, R.; Schilling, S.; Varela, J.C.; McDaniel, M.; Horn, M. Air quality at Devils Postpile National Monument, Sierra Nevada Mountains, California, USA. Aerosol Air Qual. Res. 2016, 16, 2315-2332. [CrossRef]

15. Kunzli, N.; Avol, E.; Wu, J.; Gauderman, W.J.; Rappaport, E.; Millstein, J.; Bennion, J.; McConnell, R.; Gilliland, F.D.; Berhane, K. Health effects of the 2003 Southern California wildfires on children. Am. J. Respir. Crit. Med. 2006, 174, 1221-1228. [CrossRef]

16. Phuleria, H.C.; Fine, P.M.; Zhu, Y.; Sioutas, C. Air quality impacts of the October 2003 Southern California wildfires. J. Geophys. Res. Atmos. 2005, 110, D07S20. [CrossRef]

17. Pausas, J.G.; Parr, C.L. Towards an understanding of the evolutionary role of fire in animals. Evol. Ecol. 2018, 32, 113-125. [CrossRef]

18. Shakesby, R. Post-wildfire soil erosion in the Mediterranean: Review and future research directions. Earth Sci. Rev. 2011, 105, 71-100. [CrossRef]

19. Moody, J.A.; Shakesby, R.A.; Robichaud, P.R.; Cannon, S.H.; Martin, D.A. Current research issues related to post-wildfire runoff and erosion processes. Earth Sci. Rev. 2013, 122, 10-37. [CrossRef]

20. DeBano, L.F. The role of fire and soil heating on water repellency in wildland environments: A review. J. Hydrol. 2000, 231, 195-206. [CrossRef]

21. Ravi, S.; D'Odorico, P.; Zobeck, T.M.; Over, T.M. The effect of fire-induced soil hydrophobicity on wind erosion in a semiarid grassland: Experimental observations and theoretical framework. Geomorphology 2009, 105, 80-86. [CrossRef]

22. Debano, L.F.; Krammes, J. Water repellent soils and their relation to wildfire temperatures. Hydrol. Sci. J. 1966, 11, 14-19. [CrossRef]

23. Letey, J. Causes and consequences of fire-induced soil water repellency. Hydrol. Process. 2001, 15, 2867-2875. [CrossRef]

24. Doerr, S.; Shakesby, R.; Blake, W.; Chafer, C.; Humphreys, G.; Wallbrink, P. Effects of differing wildfire severities on soil wettability and implications for hydrological response. J. Hydrol. 2006, 319, 295-311. [CrossRef]

25. Jordán, A.; Zavala, L.M.; Mataix-Solera, J.; Doerr, S.H. Soil water repellency: Origin, assessment and geomorphological consequences. Catena 2013, 108, 1-5. [CrossRef]

26. Debano, L.; Letey, J. Infiltrometer studies of water repellent soils on the east slopeof the Sierra Nevada. In Proceedings of the Symposium on Water Repellent Soils, Riverside, CA, USA, 6-10 May 1969; University of California: Riverside, CA, USA, 1969.

27. DeBano, L.; Mann, L.; Hamilton, D. Translocation of hydrophobic substances into soil by burning organic litter. Soil Sci. Soc. Am. J. 1970, 34, 130-133. [CrossRef]

28. Savage, S.; Osborn, J.; Letey, J.; Heaton, C. Substances contributing to fire-induced water repellency in soils. Soil Sci. Soc. Am. J. 1972, 36, 674-678. [CrossRef]

29. Savage, S. Mechanism of fire-induced water repellency in soil. Soil Sci. Soc. Am. J. 1974, 38, 652-657. [CrossRef]

30. DeBano, L.; Savage, S.; Hamilton, D. The transfer of heat and hydrophobic substances during burning. Soil Sci. Soc. Am. J. 1976, 40, 779-782. [CrossRef]

31. Krammes, J.; DeBano, L. Soil wettability: A neglected factor in watershed management. Water Resour. Res. 1965, 1, 283-286. [CrossRef]

32. Scholl, D.G. Soil wettability and fire in Arizona chaparral. Soil Sci. Soc. Am. J. 1975, 39, 356-361. [CrossRef]

33. DeBano, L.F. Water Repellent Soils: A State-of-the-Art; US Department of Agriculture, Forest Service, Pacific Southwest Forest and Range Experiment Station: Portland, OR, USA, 1981; Volume 46.

34. Morley, C.; Mainwaring, K.; Doerr, S.; Douglas, P.; Llewellyn, C.; Dekker, L. Organic compounds at different depths in a sandy soil and their role in water repellency. Soil Res. 2005, 43, 239-249. [CrossRef]

35. Roy, J.; McGill, W. Flexible conformation in organic matter coatings: An hypothesis about soil water repellency. Can. J. Soil Sci. 2000, 80, 143-152. [CrossRef]

36. Mainwaring, K.; Hallin, I.; Douglas, P.; Doerr, S.; Morley, C.P. The role of naturally occurring organic compounds in causing soil water repellency. Eur. J. Soil Sci. 2013, 64, 667-680. [CrossRef]

37. Simkovic, I.; Dlapa, P.; Doerr, S.H.; Mataix-Solera, J.; Sasinkova, V. Thermal destruction of soil water repellency and associated changes to soil organic matter as observed by FTIR spectroscopy. Catena 2008, 74, 205-211. [CrossRef]

38. Atanassova, I.; Doerr, S. Organic compounds of different extractability in total solvent extracts from soils of contrasting water repellency. Eur. J. Soil Sci. 2010, 61, 298-313. [CrossRef]

39. Atanassova, I.; Doerr, S. Changes in soil organic compound composition associated with heat-induced increases in soil water repellency. Eur. J. Soil Sci. 2011, 62, 516-532. [CrossRef]

40. Uddin, S.M.; Daniel, N.R.; Harper, R.J.; Henry, D.J. Why do biogenic volatile organic compounds (BVOCs) derived from vegetation fire not induce soil water repellency? Biogeochemistry 2017, 134, 147-161. [CrossRef]

41. Uddin, S.M.; Harper, R.J.; Henry, D.J. Contribution of binary organic layers to soil water repellency: A molecular level perspective. J. Phys. Chem. 2019, 123, 7518-7527. [CrossRef] [PubMed] 
42. Urban, R.; Alves, C.; Allen, A.; Cardoso, A.; Campos, M. Organic aerosols in a Brazilian agro-industrial area: Speciation and impact of biomass burning. Atmos. Res. 2016, 169, 271-279. [CrossRef]

43. Samburova, V.; Connolly, J.; Gyawali, M.; Yatavelli, R.L.N.; Watts, A.C.; Chakrabarty, R.K.; Zielinska, B.; Moosmüller, H.; Khlystov, A. Polycyclic aromatic hydrocarbons in biomass-burning emissions and their contribution to light absorption and aerosol toxicity. Sci. Total Environ. 2016, 568, 391-401. [CrossRef]

44. Simoneit, B.R.T. Biomass burning-A review of organic tracers for smoke from incomplete combustion. Appl. Geochem. 2002, 17, 129-162. [CrossRef]

45. Fine, P.M.; Cass, G.R.; Simoneit, B.R. Chemical characterization of fine particle emissions from the fireplace combustion of wood types grown in the Midwestern and Western United States. Environ. Eng. Sci. 2004, 21, 387-409. [CrossRef]

46. Wu, Y.; Zhang, N.; Slater, G.; Waddington, J.M.; de Lannoy, C.-F. Hydrophobicity of peat soils: Characterization of organic compound changes associated with heat-induced water repellency. Sci. Total Environ. 2020, 714, 136444. [CrossRef]

47. Rodríguez-Alleres, M.; Varela, M.; Benito, E. Natural severity of water repellency in pine forest soils from NW Spain and influence of wildfire severity on its persistence. Geoderma 2012, 191, 125-131. [CrossRef]

48. Badía-Villas, D.; González-Pérez, J.A.; Aznar, J.M.; Arjona-Gracia, B.; Martí-Dalmau, C. Changes in water repellency, aggregation and organic matter of a mollic horizon burned in laboratory: Soil depth affected by fire. Geoderma 2014, 213, 400-407. [CrossRef]

49. Zavala, L.M.; González, F.A.; Jordán, A. Fire-induced soil water repellency under different vegetation types along the Atlantic dune coast-line in SW Spain. Catena 2009, 79, 153-162. [CrossRef]

50. Zavala, L.M.; Granged, A.J.; Jordán, A.; Bárcenas-Moreno, G. Effect of burning temperature on water repellency and aggregate stability in forest soils under laboratory conditions. Geoderma 2010, 158, 366-374. [CrossRef]

51. Varela, M.; Benito, E.; Keizer, J. Effects of wildfire and laboratory heating on soil aggregate stability of pine forests in Galicia: The role of lithology, soil organic matter content and water repellency. Catena 2010, 83, 127-134. [CrossRef]

52. Shillito, R.M.; Berli, M.; Ghezzehei, T.A. Quantifying the Effect of Subcritical Water Repellency on Sorptivity: A Physically Based Model. Water Resour. Res. 2020, 56, e2020WR027942. [CrossRef]

53. Mehadi, A.; Moosmüller, H.; Campbell, D.E.; Ham, W.; Schweizer, D.; Tarnay, L.; Hunter, J. Laboratory and field evaluation of real-time and near real-time PM2.5 smoke monitors. J. Air Waste Manag. Assoc. 2020, 70, 158-179. [CrossRef]

54. Stephens, S.L. Fire history differences in adjacent Jeffrey pine and upper montane forests in the eastern Sierra Nevada. Int. J. Wildland Fire 2001, 10, 161-167. [CrossRef]

55. Jenkinson, J.L. Jeffrey pine, Pineaceae, pine family. In Silvics of North American Conifers; United States Department of Agriculture: Washington, DC, USA, 1990; Volume 654, pp. 359-369.

56. Kwok, D.Y.; Neumann, A.W. Surface Characterization Methods: Principles, Techniques, and Applications; CRC Press: Boca Raton, FL, USA, 1999; Volume 87, pp. 37-86.

57. Chau, T. A review of techniques for measurement of contact angles and their applicability on mineral surfaces. Miner. Eng. 2009, 22, 213-219. [CrossRef]

58. Watts, A.C.; Samburova, V.; Moosmüller, H. Criteria-Based Identification of Important Fuels for Wildland Fire Emission Research. Atmosphere 2020, 11, 640. [CrossRef]

59. Brown, P.M.; Wu, R. Climate and disturbance forcing of episodic tree recruitment in a southwestern ponderosa pine landscape. Ecology 2005, 86, 3030-3038. [CrossRef]

60. Moore, M.M.; Huffman, D.W.; Fulé, P.Z.; Covington, W.W.; Crouse, J.E. Comparison of historical and contemporary forest structure and composition on permanent plots in southwestern ponderosa pine forests. For. Sci. 2004, 50, $162-176$.

61. Nabhan, G.P. Ecological Restoration of Southwestern Ponderosa Pine Forests; Island Press: Washington, DC, USA, $2003 ;$ Volume 2.

62. O'Dell, K.; Hornbrook, R.S.; Permar, W.; Levin, E.J.; Garofalo, L.A.; Apel, E.C.; Blake, N.J.; Jarnot, A.; Pothier, M.A.; Farmer, D.K. Hazardous Air Pollutants in Fresh and Aged Western US Wildfire Smoke and Implications for Long-Term Exposure. Environ. Sci. Technol. 2020, 54, 11838-11847. [CrossRef]

63. Kelly, H.; Schmidt, S. As Wildfire Smoke Becomes a Part of Life on the West Coast, So Do Its Health Risks. Available online: https:/ / www.washingtonpost.com/nation/2020/09/16/smoke-air-west/ (accessed on 28 December 2020).

64. Tian, J.; Chow, J.C.; Cao, J.; Han, Y.; Ni, H.; Chen, L.W.A.; Wang, X.; Huang, R.; Moosmüller, H.; Watson, J.G. A biomass combustion chamber: Design, evaluation, and a case study of wheat straw combustion emission tests. Aerosol Air Qual. Res. 2015, 15, 2104-2114. [CrossRef]

65. Bhattarai, C.; Samburova, V.; Sengupta, D.; Iaukea-Lum, M.; Watts, A.C.; Moosmüller, H.; Khlystov, A.Y. Physical and chemical characterization of aerosol in fresh and aged emissions from open combustion of biomass fuels. Aerosol Sci. Technol. 2018, 52, 1266-1282. [CrossRef]

66. Doerr, S.H.; Shakesby, R.A. Soil Water Repellency. In Handbook of Soil Sciences; Huang, P.M., Li, Y., Sumner, M., Eds.; CRC Press: Boca Raton, FL, USA, 2012.

67. Alberts, J.J.; Takács, M. Total luminescence spectra of IHSS standard and reference fulvic acids, humic acids and natural organic matter: Comparison of aquatic and terrestrial source terms. Org. Geochem. 2004, 35, 243-256. [CrossRef]

68. International Humic Substances Society. Available online: http:/ / humic-substances.org/the-third-batch-of-suwannee-riverhumic-and-fulvic-acids (accessed on 30 December 2020). 
69. Larsen, I.J.; MacDonald, L.H.; Brown, E.; Rough, D.; Welsh, M.J.; Pietraszek, J.H.; Libohova, Z.; de Dios Benavides-Solorio, J.; Schaffrath, K. Causes of post-fire runoff and erosion: Water repellency, cover, or soil sealing? Soil Sci. Soc. Am. J. 2009, 73, 1393-1407. [CrossRef]

70. Graber, E.R.; Rudich, Y. Atmospheric HULIS: How humic-like are they? A comprehensive and critical review. Atmos. Chem. Phys. 2006, 6, 729-753. [CrossRef]

71. Piccolo, A. The supramolecular structure of humic substances: A novel understanding of humus chemistry and implications in soil science. Adv. Agron. 2002, 75, 57-134.

72. Sutton, R.; Sposito, G. Molecular structure in soil humic substances: The new view. Environ. Sci. Technol. 2005, 39, 9009-9015. [CrossRef]

73. Sollins, P.; Homann, P.; Caldwell, B.A. Stabilization and destabilization of soil organic matter: Mechanisms and controls. Geoderma 1996, 74, 65-105. [CrossRef] 